Egon Schneider

Die Klage im Zivilprozess 



\section{Die Klage im \\ Zivilprozess}

mit Klageerwiderung und Replik

von

Dr. Egon Schneider

Richter am OLG a.D., Rechtsanwait, Much

3. Aullage

2007

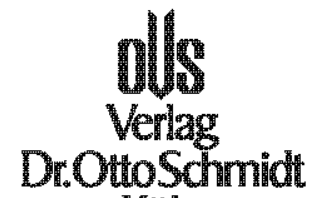

Koln 
Bibliografusche Information

der Deatschen Nationalbibliothek

Die Deutsche Nationalbibliothek verzeichnet diese

Publikation in der Deutschen Nationalbibliografie; detaillierte bibliografische Daten sind in Intemet über http://dnb.d-ab.de abrufbar.

Verlag Dr. Otto Schmidt KG

Gustay-Heinemann-Ufer 58, 50968 Köln

Tel. 02 21/93738 01, Fax 02 21/93738 943

info@otto-schmidt.de

www.otto-schmidtde

ISBN 978-3-504-47079-1

C2007 by Verlag Dr. Otto Schmidt KG, Köln

Das Werk einschließlich aller seiner Teile ist urheberrechtlich geschützt. Jede Verwertung, die nicht ausdrücklich vorn Urheberrechtsgesetz zugelassen ist, bedarf der vorherigen Zustimmung des Verlages. Das gilt insbesondere für Vervielfältigungen, Bearbeitungen, Obersetzungen, Mikroverfilmungen und die Einspeicherung und Verarbeitung in elektronischen Systemen.

Das verwendete Papier ist aus chlorfrei gebleichten Rohstoffen hergestellt, holz- und säurefrei, alterungsbeständig und umweltfreundlich.

Einbandgestaltung: Jan P. Lichtenford, Mettrnann

Gesamtherstellung: Bercker, Kevelaer

Printed in Germany 
Für Doris, Annegret und Ekko 
